\title{
SISTEMA DE GESTÃO E METODOLOGIA COM BASE EM COMPETÊNCIAS: RESSIGNIFICANDO A ATUAÇÃO DOCENTE
}

Sérgio Roberto Arruda ${ }^{1}$

\begin{abstract}
RESUMO
O artigo pretende mostrar como a utilização de duas metodologias diferentes exige um novo papel para os professores. O objetivo é articular uma metodologia de planejamento com uma metodologia pedagógica baseada na competência. A referência é a PDCA, por quanto concerne o planejamento, e educação baseada em competências. Esta nova forma de ensino, que por sinal, está sendo adotada em vários países para lidar com um novo perfil de estudantes e uma nova exigência do mundo do trabalho e com o advento de novas tecnologias da informação e da comunicação, exige um novo posicionamento dos professores. O professor deve abandonar a idéia de que ele é a principal fonte de conhecimento e que ele é o responsável para transmitir o seu conhecimento para o aluno. Sua nova posição é a de ser o mediador entre o aluno e o conhecimento. Para assumir esta nova posição ele tem funções diferentes para desempenhar, como: definir as competências, planejar tarefas através das quais as competências serão desenvolvidas pelos alunos, verificar a efetiva apropriação de competências e planejar novas tarefas quando a competência adequada não foi desenvolvida. Um estudo de caso é apresentado brevemente o que mostra uma melhoria significativa no desempenho dos alunos em termos de conhecimentos, habilidades e competências sociais que mostram a pertinência do modelo adotado.
\end{abstract}

Palavras chaves: Sistema de gestão. Competências. Atuação docente.

${ }^{1}$ Mestre, e-mail: arruda@sc.senai.br 


\section{INTRODUÇÃO}

Trabalho encomendado pelo Governo do Estado de Santa Catarina e realizado por equipe de experts da Organização para a Cooperação e Desenvolvimento Econômico (OCDE) ao longo dos anos de 2007 a 2009, apontou diversas oportunidades de melhoria na educação catarinense; no entanto, uma recomendação - entre muitas - se sobressaiu: a questão da gestão. Foi tema que se tornou praticamente recorrente em todos os capítulos do documento.

Aliada a essa questão, outro aspecto da educação estadual que mereceu destaque foi a abordagem metodológica. Nesse sentido, o Serviço Nacional de Aprendizagem Industrial (SENAI) Nacional e mais especificamente o SENAI de Santa Catarina definiu como metodologia mais adequada a ser usada não só na educação profissional, mas também na educação propedêutica, a metodologia de educação com base em competências.

O objetivo deste artigo é articular, estes dois aspectos da educação: a gestão do processo pedagógico e a abordagem metodológica, e propor ao docente um olhar renovado para a gestão do processo de ensino e de aprendizagem. Para tanto, o docente precisará mobilizar capacidades que extrapolam o domínio técnico.

Com vista a atender essa demanda cada vez mais crescente e mais premente, o SENAI/ SC vem trabalhando com o conceito de Academia SENAI que tem como objetivo preparar seus docentes em quatro dimensões consideradas fundamentais, apresentadas na figura 1, a seguir. Neste artigo, será dada ênfase nas competências pedagógicas e de gestão.

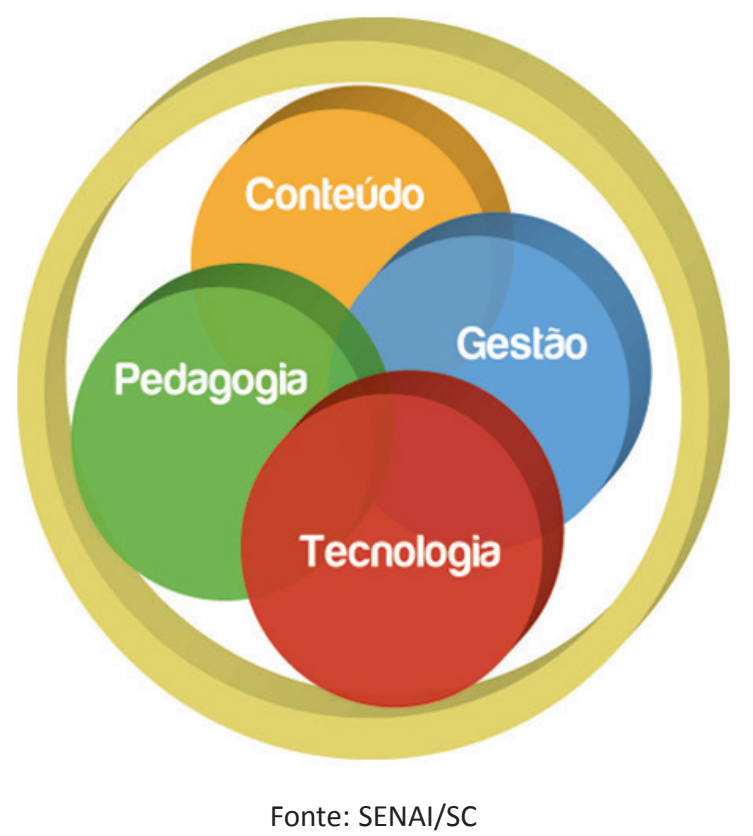




\section{ARTICULANDO COMPETÊNCIAS}

Para se compreender a articulação que se está propondo, é necessário antes compreender as etapas percorridas no processo de estruturação de um curso da Educação Profissional. A figura 2, logo a seguir, apresenta um esquema simplificado da criação e operação de um curso ancorado na educação com base em competências.

Figura 2: Fluxo de criação e implantação de um curso

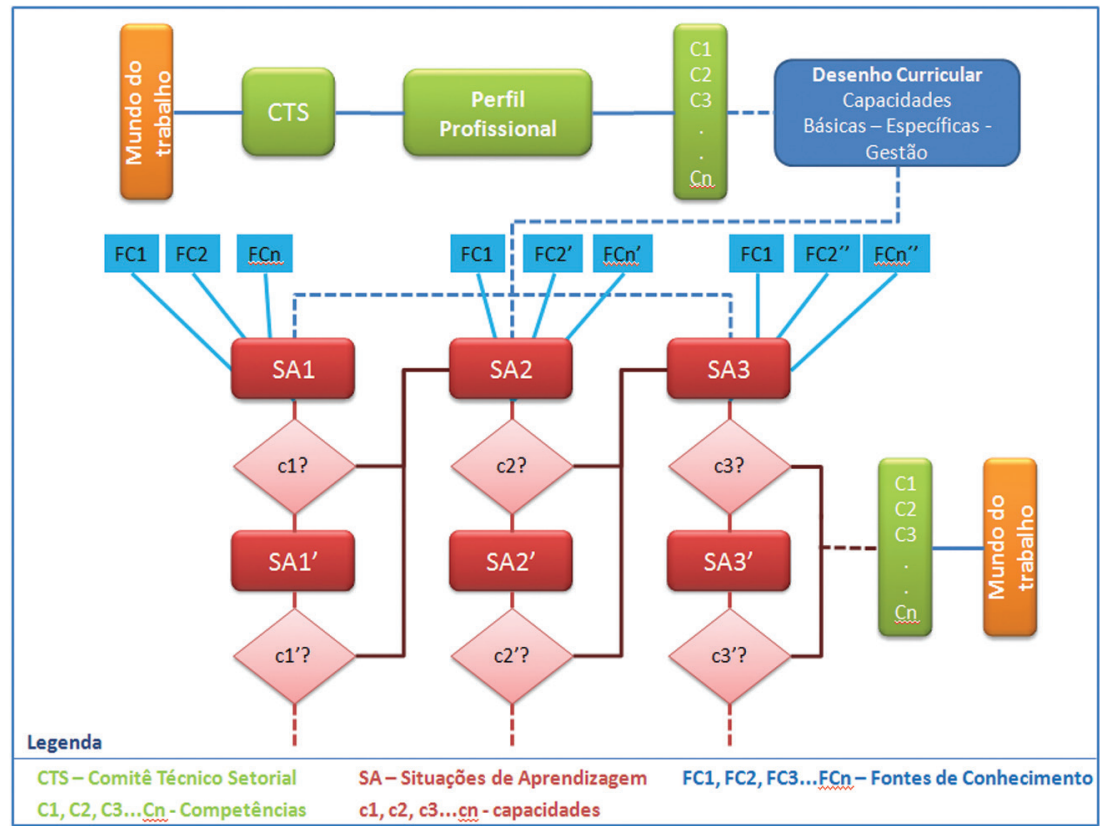

Fonte: SENAI/SC

Esse esquema pode apresentar uma simplificação exagerada, porém servirá para mostrar a metodologia de criação de um curso e a construção do perfil profissional, desde o início, que tem sua origem no mundo do trabalho e traz, como demanda, as competências requeridas para um profissional devidamente qualificado. Essa demanda é identificada e definida pelo Comitê Técnico Setorial, constituído por especialistas de empresas, do SENAI, de Sindicatos e de Organismos de Classe. Definidas as competências, estas são transformadas em capacidades devidamente traduzidas pela estrutura curricular.

Passadas as fases de aprovação, o curso passa então para a operacionalização. A metodologia da educação com base em competências usa como âncora as situações de aprendizagem, o que na figura 2 está representada por SA1, SA2, ....SAn. São atividades desafiadoras que devem estar contextualizadas, ter valor sociocultural, evocar saberes e propor a solução de um problema que exija tomada de decisão, testagem de hipóteses 
e transferências de aprendizagens, na busca de um resultado tangível e passível de ser alcançado e compreendido. Essas atividades precisam despertar nos estudantes interesse e motivação, para que amparados pelas fontes de conhecimento desenvolvam as capacidades necessárias. Estas diversas fontes, que são representadas na figura por: FC1, FC2 .....FCn, podem ser: o docente, bibliografias, a rede por meio de seus bancos de dados e redes sociais etc. Onde o conhecimento estiver disponível, o aluno poderá buscá-lo. Importa destacar que o docente medeia esse processo durante toda a resolução da situação de aprendizagem, da elaboração da situação de aprendizagem à orientação para pesquisa, ao monitoramento do desenvolvimento individual e coletivo, ao replanejar ações que atendam aqueles alunos que estejam com dificuldades

Considerando que cada situação de aprendizagem deve dar oportunidade para que uma ou mais capacidades sejam desenvolvidas, a etapa seguinte é verificar se as capacidades foram efetivamente desenvolvidas, o que está representado por c1?.É a fase de verificação do aproveitamento, fase na qual o docente verifica se aquelas competências prevista no perfil profissional foram adquiridas. Se isso ocorrer, o estudante deverá passar para uma nova situação de aprendizagem com novas capacidades sendo desenvolvidas. Se não ocorrer, nova situação de aprendizagem deve ser programada para aquele estudante que não desenvolveu as capacidades previstas. Este processo será repetido até que as competências tenham sido adquiridas. Vale lembrar que para favorecer o alcance desse resultado os docentes devem agir articuladamente entre si, bem como com o coordenador do curso, coordenador pedagógico, bibliotecário e demais envolvidos no processo, permitindo ao trabalho escolar caminhar para um desenvolvimento integrado e interdisciplinar. Deve ser notado que há nesta descrição um Plan-Do-Check-Act (PDCA) implícito sendo utilizado. Antes, porém, de passar à figura que ilustra essa descrição, importante fazer uma breve explicação a respeito dessa metodologia.

O PDCA é uma metodologia de planejamento, execução, controle e ações de melhoria, identificada pelas iniciais das palavras inglesas Plan - P, Do - D, Control - C e Act - A, cujo ciclo completo implica planejar, executar o planejado, ter indicadores que possam ser controlados e quando as metas não são atingidas, programar ações de melhoria. Com isso inicia-se um novo ciclo. Uma evolução do PDCA é o PDCS que significa que quando as metas são atingidas e o ciclo já se estabilizou, as práticas adotadas são sistematizadas e passam a ser processos consolidados.

Ao retomar a descrição já iniciada, pode-se observar, na figura a seguir, a ocorrência não de um, mas de vários PDCAs acontecendo desde o início de elaboração de um curso até seu desenvolvimento didático-pedagógico. 
Figura 3: Ciclo do PDCA

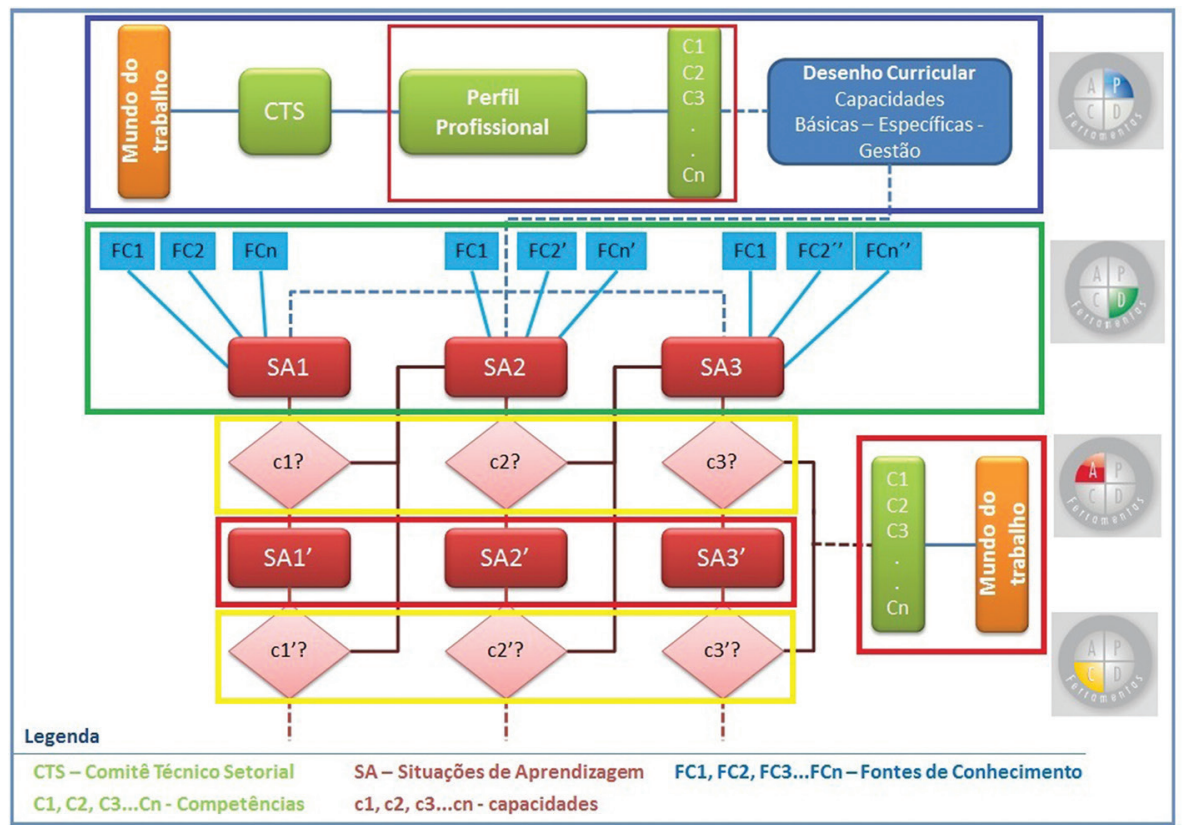

Fonte: SENAI/SC

O ciclo demarcado pela cor azul demonstra a etapa de planejamento do perfil profissional e da transformação deste perfil num desenho curricular, trata-se da fase $\mathrm{P}$ do processo. A fase $D$ é representada pelas situações de aprendizagem e pelo desempenho do estudante e está demarcada pela cor verde. A fase C, demarcada pela cor amarela, está representando as verificações do desenvolvimento das capacidades. A fase $A$ são as novas situações de aprendizagem elaboradas com o propósito de fornecer nova oportunidade para desenvolver aquelas capacidades previstas e não desenvolvidas por todos os estudantes.

Esse ciclo se repete até que o grande PDCA se feche e as competências definidas no projeto de curso sejam alcançadas por todos os estudantes. Caso isto se concretize o profissional estará plenamente capacitado a entrar no mundo do trabalho. O fechamento do ciclo do PDCA completa todo o processo de gestão do curso em análise, que pode ser um curso de qualificação, aprendizagem industrial, técnico, superior ou mesmo pósgraduação.

Logo, o PDCA, que é um método simples de fazer planejamento, execução, verificação e melhorias em qualquer processo, torna-se ferramenta de gestão poderosa inclusive e principalmente nos processos educacionais. 


\section{REFLEXÕES ACERCA DA ATUAÇÃO DOCENTE}

Como última fase do artigo cabe responder a seguinte pergunta: e o docente como fica nesse processo?

Ao docente caberá renovar o olhar sobre o monitoramento do processo de ensino e de aprendizagem, o que poderá ser feito à luz do PDCA. Ao planejar o processo, isto é, planejar as situações de aprendizagem, fazer as verificações, servir de orientador quanto às fontes disponíveis de conhecimento, e garantidor do atingimento das competências, ele estará consolidando seu papel de mediador do processo ensino e de aprendizagem, transformando o estudante, de objeto em ator e sujeito de seu próprio aprendizado. Essa mudança de posição do docente requer que o mesmo abdique de ser a única fonte de conhecimento e o transmissor do mesmo.

Como exemplo dessa metodologia, já implantada em alguns cursos do SENAI/SC, pode ser apresentado o curso técnico de programação no SENAI de Joinville. Trata-se de um curso técnico articulado ao Ensino Médio, cujos docentes foram às empresas da região, em parceria com técnicos dessas empresas, selecionaram diversos projetos ou parte de projetos que pudessem ser desenvolvidos pelos estudantes. Dividiram a turma em dois grupos e atribuíram a cada grupo uma função definida: um grupo tem a função de analista de sistemas e o outro desempenha o papel de programador. A cada semana as funções se alternam. No final do curso os técnicos das empresas são convidados a participar do encerramento e da avaliação final.

Os resultados foram: inadimplência zero, frequência praticamente $100 \%$ e índice de reprovação também nulo. Além do alcance das competências previstas,os estudantes tiveram um desenvolvimento extremamente valioso no que se refere às capacidades sociais, desenvolvendo capacidade de trabalho em grupo e necessidade de conviver com diversidade de opiniões e de formações sociais, econômicas e culturais. 


\title{
MANAGEMENT SYSTEM AND METHODOLOGY BASED ON COMPETENCES: NEW MEANING TO TEACHING PERFORMANCE
}

\begin{abstract}
The article intends to show how the use of two different methodologies require a new role for teachers. The aim is to articulate a methodology of planning with a pedagogical methodology based on competence. The reference is to PDCA as far as planning is concerned and competence based education. This new way of teaching, that by the way, is being adopted in several countries to deal with a new profile of students and a new demands of the world of labor and the advent of new information and communication technologies, requires a new positioning of teachers. The teacher must abandon the idea that he is the main source of knowledge and that he is responsible to transmit his knowledge to the student. His new position is to be the mediator between the student and the knowledge. To assume this new position he has different roles to carry on, like: defining the competences, planning tasks through which the competences will be developed by students, checking the effective appropriation of competences, and plan new tasks when the proper competence was not developed. A case study is briefly presented which shows a significant improvement in student performance in terms of knowledge, abilities, and social skills showing the pertinence of the model adopted.
\end{abstract}

Key-words: Management system. Competences. Teaching performance. 


\section{REFERÊNCIAS}

ADÃO, N. M. L. et al. Escola sistêmica:relato de uma práxis no SENAI de Joinville-SC. E-Tech: Tecnologias para Competividade Industrial, Florianópolis, n. esp. Educação, p.91104, 2012.

AVALIAÇÕES de políticas nacionais de educação: Estado de Santa Catarina Brasil. [S.I.]: OCDE, 2010. 373 p. ISBN 9789264091368.

CAMPOS, V. F. Gerenciamento da Rotina do Trabalho do dia-a-dia. Nova Lima: INDG Tecnologia e Serviços Ltda, 2004.

TQC: controle de qualidade total (no estilo japonês). 5. ed. Belo Horizonte: Fundação Christiano Ottoni, 1994.

MATOS, Osvair; ARRUDA, Sérgio Roberto. Metodologia SENAI para formação profissional com base em competências: um estudo de caso sobre a implantação deste método no departamento regional do SENAI de Santa Catarina. E-Tech: Tecnologias para Competividade Industrial, Florianópolis, n. esp. Educação, p. 31-49, 2012.

PERRENOUD, P. Construir as competências desde a escola. Trad. Bruno Charles Magne. Porto Alegre: Artes Médicas Sul, 1999.

RASZL, Simone Moraes et al. Gestão da Qualidade na Educação. E-Tech: Tecnologias para Competividade Industrial, Florianópolis, n. esp. Educação, p. 15-29, 2012.

SERVIÇO NACIONAL DE APRENDIZAGEM INDUSTRIAL. Departamento Nacional. Elaboração de perfis profissionais por comitês técnicos setoriais. 3. ed. Brasília, DF: SENAI/DN, 2009. 73 p. (Formação profissional baseada em competências; v.1). ISBN 9788575193044.

Departamento Nacional. Elaboração de desenho curricular. 3. ed. Brasília, DF: SENAI/DN, 2009. 64 p. (Formação profissional baseada em competências; v.2). ISBN 9788575193075.

Departamento Nacional. Norteador da prática pedagógica. 3. ed. Brasília, DF: SENAI/DN, 2009. 107 p. (SENAI Formação Profissional por Competências; v3). ISBN 9788575193068.

SOBRE a escola que temos e a escola que queremos: relatório sobre estudo do documento avaliações de políticas nacionais de educação: Estado de Santa Catarina. Florianópolis: SENAI/SC, 2011. 


\section{SOBRE O AUTOR}

Formado em Engenharia Elétrica pela UFRGS (1966), mestrado em Electrical
Machines and Power Systems pela Universidade de Londres (1970).
Especialização em Engenharia de Segurança do Trabalho pela UDESC (1974).
Sua carreira profissional iniciou-se como Professor do Departamento de
Engenharia Elétrica em 1968, onde permaneceu até 1994, quando se
aposentou como Professor Titular. Assumiu o posto de Chefe de Departamento
de Engenharia Elétrica da UFSC nos períodos de 1992 a 1994 e 1971 a 1974.
De 1975 a 1980 foi Diretor do Centro Tecnológico da UFSC e Diretor Presidente
da Fundação para Ensino de Engenharia - EESC.
De 1990 a 1992, desenvolveu atividades como Diretor de Desenvolvimento
Científico e Tecnológico do Governo do Estado.
No período de 1994 a 1996 foi pesquisador do CNPq/RHAE. Exerceu, também,
função de Diretor na Iniciativa Privada e Engenheiro na CELESC. Foi Diretor
Superintendente do SENAI-CTAI no período de 1996 a 1998.
Desde setembro de 1998 exerce o cargo de Diretor Regional do SENAI - Serviço
Nacional de Aprendizagem Industrial de Santa Catarina. É Conselheiro do
Conselho de Curadores da UFSC, do Conselho Estadual de Educação de SC
(CEE-SC) e do SEBRAE-SC.

